\title{
Organização da informação em bibliotecas escolares: contribuições para a competência informacional infantil
}

\author{
Organization of information in school libraries: contributions to children's information \\ literacy
}

Niliane Cunha de Aguiar Bibliotecária. Mestranda em Ciência da Informação pela Universidade Federal de Pernambuco - UFPE. E-mail: nilianeaguiar@yahoo.com.br

\begin{abstract}
Resumo
A autonomia indispensável para a construção da competência da informacional infantil encontra na Biblioteca Escolar um lócus privilegiado desde que os recursos informacionais disponíveis estejam devidamente sistematizados e organizados. Sobretudo, é preciso utilizar na Biblioteca escolar, um sistema de organização da informação e uma terminologia condizente com o estágio de desenvolvimento dos seus usuários para promover constantemente o interesse pela leitura de forma lúdica e atrativa. Assim sendo, serão favorecidas a assimilação dos conteúdos e a formação da consciência crítica desde a infância.
\end{abstract}

Palavras-chave: Organização da Informação. Biblioteca Escolar. Competência Informacional Infantil.

\begin{abstract}
The autonomy necessary for the construction of informational children's competence in the school library is a privileged place since the available information resources are properly organized and systematized. Above all, you must use the school library, a system of organizing information and terminology consistent with the developmental stage of its users to constantly promote interest in reading in a playful and attractive. Thus, will be favored assimilation of contents and the formation of critical consciousness since childhood.
\end{abstract}

Keywords: Organization of Information. School Library. Information Literacy for Children.

\section{Introdução}

Para adaptar as crianças à Sociedade da Informação e do Conhecimento, faz-se necessário oferecer a elas recursos informacionais que as introduzam neste mundo em constante evolução e transformação. Mais que habilidades tecnológicas, é imprescindível estabelecer condições para que este público desenvolva a assimilação de conteúdos e estabeleça uma consciência crítica diante da grande quantidade de informações disponíveis.

Neste contexto, acredita-se que organização da informação nas bibliotecas escolares pode ser um fator fundamental para promover a autonomia indispensável para a construção da competência informacional infantil. 
O presente artigo pretende averiguar a veracidade dessa hipótese através de uma revisão de literatura sobre os processos e instrumentos de organização da informação utilizados em bibliotecas escolares, na expectativa de promover uma reflexão sobre a importância desses, para a formação da competência informacional em crianças dos anos iniciais do ensino fundamental.

O fato é que, se por muito tempo, a criança não foi vista como usuária potencial de informação, e sim como depositária de conteúdos preestabelecidos pelos currículos escolares.

E conforme afirma, Antunes (2002, p. 10),

O homem que vai a escola no século XXI é, finalmente visto de maneira diferente de como o percebiam cem anos antes. Trata-se de uma criatura holística, dotada de um poder criativo incomensurávelmente amplo, pronta para ser estimulada por uma nova escola [...] que compreenda a plenitude de sua diversidade. [...]

Atualmente, diante das transformações geradas pelas tecnologias da informação e comunicação na formação da sociedade da informação, as crianças também são atingidas e hoje desde muito cedo possuem acesso aos diversos recursos informacionais. Estas transformações no âmbito global exigem um público infantil mais independente e autossuficiente no que diz respeito à busca por conhecimento. O acesso à Internet abriu um vasto número de informações, nem sempre assimiladas pelas crianças, mas que inevitavelmente estão ao alcance das suas mãos.

Por esses motivos, torna-se cada vez mais necessário refletir sobre as melhores práticas de ensinar ao público infantil, formas de recuperação, acesso e utilização das informações disponíveis.

Tal reflexão deve ser feita a partir da biblioteca escolar, uma vez que esta é, segundo Caldin (2003) o local por excelência para apresentar a leitura como uma atividade natural e prazerosa, posto que, para muitas crianças, configura-se como a única oportunidade de ter acesso aos livros que não são didáticos, e atualmente também é para muitas o único lugar que podem ter acesso à Internet.

Conforme declara a International Federation of Libraries Associations (IFLA) (2005), é missão da biblioteca escolar proporcionar informações e ideias fundamentais capazes de tornar seus usuários bem sucedidos na sociedade atual, baseada na informação e no conhecimento. 
Por esses motivos, a biblioteca escolar, através dos profissionais que nela atuam, precisa se preparar para conhecer as necessidades informacionais das crianças de hoje, objetivando a promoção da competência informacional infantil, através de serviços, sistemas de recuperação da informação e até mesmo linguagens de indexação específicas para este público, para assim proporcionar às crianças o acesso às informações que precisam, através de recursos que as torne mais autônomas, independentes e pró-ativas, qualidades essenciais para a sobrevivência numa sociedade exigente e competitiva.

\section{Organização da Informação em bibliotecas escolares}

Em concordância com a afirmação de Milanesi (1989), a eficiência de uma biblioteca deve ser medida pela rapidez com que é possível localizar um livro, e desta forma, entende-se que a organização da informação nas bibliotecas se faz, exatamente para atender a esse anseio, ou seja, para poupar o tempo do leitor.

A organização da informação será aqui entendida conforme Fujita (2003) como processo relacionado ao tratamento intelectual da informação que inclui a análise descritiva e a análise temática da informação, através das operações de catalogação, classificação e indexação.

\subsection{Catalogação}

A catalogação em bibliotecas escolares é efetuada pelos mesmos motivos das demais bibliotecas: recuperar informações. No entanto, há especificidades da realidade das bibliotecas escolares (brasileiras) que precisam ser levadas em conta: a primeira é que os catalogadores nem sempre são profissionais habilitados para tal atividade; a segunda, que é consequência da primeira, é o desconhecimento de que tal atividade deve ser feita em função do seu público, neste caso pouco especializado; a terceira pela falta de recursos financeiros e tecnológicos para o desenvolvimento do trabalho.

Apesar desta realidade, a catalogação do acervo existente nas bibliotecas escolares pode e deve ser feita, e neste sentido, a IFLA (2005) afirma que é vital escolher um sistema de catálogo para a biblioteca escolar, que permita a classificação e catalogação dos recursos informativos de acordo com padrões bibliográficos aceitos nacional e internacionalmente, 
pois facilita a sua inclusão em grandes redes de informação. Também recomenda que as bibliotecas escolares de comunidades locais façam parte de um catálogo coletivo, visto que tal colaboração poderá aprimorar a eficiência e a qualidade do processamento técnico dos livros.

Sobre catalogação em bibliotecas escolares, Campello (2010) apresenta as propostas elaboradas pelo Grupo de Estudo em Biblioteca Escolar da Universidade Federal de Minas Gerais UFMG em 2010, indicadores de qualidade pelos quais as bibliotecas escolares devem ter:

- No nível básico: incluídos no catálogo da biblioteca pelo menos os livros do acervo, permitindo recuperação por autor, título e assunto;

- No nível exemplar: o catálogo da biblioteca deve ser informatizado e possibilitar o acesso remoto a todos os itens do acervo; permitindo, além da recuperação por autor, título e assunto, a recuperação por outros pontos de acesso, como títulos de capítulos, disciplinas correspondentes, etc.

Pimentel (2007) sugere que nas bibliotecas escolares existam um catálogo de autor, título, assunto e um catálogo dicionário. Para a autora, estes catálogos podem estar dispostos em diferentes formas, tais como livros, folhas soltas ou fichas catalográficas, pois a escolha do melhor tipo de catálogo dependerá dos recursos disponíveis em cada biblioteca, do tamanho do seu acervo e das características dos usuários que deverão utilizá-lo.

\subsection{Classificação}

Partindo do princípio descrito por Vianna (2008, p.46), no qual afirma que "se a biblioteca escolar for organizada de acordo com um sistema que seja utilizado pela maioria das bibliotecas, a criança terá mais segurança e estímulo para explorar os acervos de outras bibliotecas", entende-se que a escolha de um sistema de classificação neste tipo de biblioteca determinará não só o uso de seu acervo, mas a formação intelectual de seus usuários.

Para a autora, uma vez que os sistemas de classificação mais utilizados em bibliotecas são a Classificação Decimal Universal (CDU) e a Classificação Decimal de Dewey (CDD), as bibliotecas escolares devem também optar por esses sistemas. Nesta mesma perspectiva, Hoffman e Pereira (2006) também afirmam que a biblioteca escolar deve ter o compromisso de educar seus usuários no uso e manuseio adequado dos documentos que compõem o seu 
acervo, tornando-os aptos a utilizarem bibliotecas em quaisquer outras instituições por eles frequentadas. Por esse motivo, as autoras, igualmente defendem o uso de princípios básicos de organização utilizados em nível nacional e internacional nas bibliotecas escolares, como forma de proporcionar aos seus usuários a compreensão dos sistemas utilizados para o controle dos acervos, bem como das regras de funcionamento em outras instituições.

A escolha do sistema classificatório para este tipo de biblioteca varia entre os autores, como exemplo, Pimentel (2007), Silva (2002) optam pela CDU, e Kuhlthau (2006) e Hilleslieini e Fachin (2000) sugerem a CDD.

Segundo Vianna (2008) algumas adaptações na classificação para o bibliotecas escolares poderão ser necessárias, mas ressalta que tão logo a criança entre na fase de leitura permanente e de busca de informação para seus trabalhos escolares, deve entender a organização dos materiais na biblioteca, e se frequentada sistemática e constantemente, possibilitará ao estudante a assimilação natural dos procedimentos necessários para explorar os materiais e informações que ela possui. Do contrário, explica a autora, a utilização de formas simplificadas de organização de seus acervos, como, por exemplo, o uso de cores para agrupar os materiais, que a princípio parece extremamente prático, pode impedir que os alunos conheçam formas consolidadas de organização de bibliotecas com as quais poderão se deparar mais tarde, em sua vida escolar.

Hilleslieini e Fachin (2000), entretanto, destacam a importância da utilização de outros recursos para a classificação na biblioteca escolar, afirmam que se deve procurar sempre tornar a recuperação da informação mais clara para os usuários mirins, e sugerem o sistema de cores, que pode ser utilizado tanto para marcar os livros como as fichas catalográficas ou os registros do computador.

Nesta mesma visão, os autores Hauenstein; Santini e Kuse (2003), também sugerem que para facilitar o entendimento da organização da biblioteca para as crianças, seja empregado um método de utilização de cores diferentes para cada assunto. Para eles, pode-se ainda utilizar diversos tons da cor escolhida para representar um determinado assunto e para identificar as subdivisões de assunto e a indicação de cores deve ser marcada no livro com uma etiqueta colorida colocada na lombada.

Este padrão de cores poderá ser utilizado, explicam Hilleslieini e Fachin (2000), colocando um cartaz em local bem visível para que os alunos possam encontrar a informação. 
E após a distribuição das cores, todos os materiais deverão ser marcados para facilitar a sua recuperação.

Leite (2001) também sugere que além de cores diferentes, a literatura infantil nas bibliotecas escolares, também seja identificada por figuras, para facilitar para as crianças o encontro com o material desejado. Em conformidade com este pensamento, Barbosa (2005, p.9) ressalta que o uso de ícones facilita a busca. Por isso, sugere: "Vamos sacudir o pó das classificações bibliográficas no que tange à ficção, e elaborar etiquetas icônicas.”.

A autora sugere ainda que abaixo do ícone sejam colocadas as três primeiras letras do sobrenome autor em caixa alta, seguidas de travessão, ou ponto, ou vírgula e a primeira letra do prenome (ou mais, quando necessário), seguida da inicial minúscula do título. Segundo a autora, várias bibliotecas europeias de acervos imensos adotam essa forma com ótimos resultados, sendo assim, acredita-se que em bibliotecas escolares, que possuem acervos em geral, bem menores, provavelmente se beneficiarão também da simplicidade.

Neste sentido, a utilização de ícones compatíveis com cada área do conhecimento, pode facilitar o acesso às informações, e desta forma,

[...] o estabelecimento dos ícones dependerá da criatividade de cada bibliotecário, uma vez que não existe padronização neste sentido. Para Geografia, por exemplo, pode ser usado um globo; para História Geral, gravura de algum fato histórico relevante; para História do Brasil: caravelas; para Ciências: um microscópio; para Biologia: um animal; para Física: uma lâmpada, ou um raio. Com certeza, ícones é que não irão faltar na imaginação de cada um e deverão estar presentes nas fichas catalográfícas, nas estantes e demais sinalizadores da Biblioteca. (HILLESLIEINI; FACHIN 2000, p.93)

Estas adaptações para um sistema de classificação especialmente planejado para as crianças podem ser capazes de favorecer aos poucos, a familiarização das crianças com a organização física e temática das coleções e desta forma, promoverá o autosserviço e diminuirá gradativamente a demanda por orientação, tornando os pequenos usuários cada vez mais seguros e independentes em relação à biblioteca, explica Leite (2001).

Por esse motivo, como observa Kieser e Fachin (2004), espera-se que uma vez tendo conquistado este usuário mirim, ele passe a ser um incentivador à melhoria da qualidade dos serviços prestados da biblioteca, visto que, este mesmo usuário pode passar a procurar mais e mais bibliotecas, pelo encanto produzido neste primeiro contato com biblioteca escolar.

Quando isso acontecer, as bibliotecas escolares finalmente prepararão as crianças para serem pesquisadoras da informação durante toda sua vida adulta. 


\subsection{Indexação}

Também na biblioteca escolar a indexação justifica-se segundo Silva (2002), pela necessidade de determinar por meio da análise documental, os conceitos que compõem os documentos, tendo em vista a possibilidade de recuperação da informação pelos usuários em suas pesquisas.

Por esse motivo, a indexação nas bibliotecas escolares deve processar-se seguindo os procedimentos comuns, sendo desejável, contudo, que a linguagem adotada seja ajustada aos diferentes níveis de escolaridade, conforme explica Costa (2009).

A autora ainda esclarece que para realizar a indexação do acervo de bibliotecas escolares de forma eficiente, será necessário redigir uma política de indexação adaptada à realidade de cada biblioteca escolar, na qual sejam inseridos todos os suportes informacionais existentes, dentre os quais, neste caso, por se tratar de um espaço de aprendizagem que, deverá contemplar jogos pedagógicos, softwares educativos, etc.

Além disto, para a autora, a primeira questão a ser considerada nesta política é a habilidade linguística das crianças e adolescentes, pois somente após o entendimento da forma como os jovens procuram e recuperam as informações será possível proporcionar uma boa qualidade na indexação (eficiente e eficaz). Isto demandará um estudo de uso e usuários da informação em bibliotecas escolares.

Outra importante questão a ser tratada, em relação à indexação em bibliotecas escolares, refere-se ao seu acervo documental, pois este além de atender aos temas dos programas curriculares, deve oferecer também, materiais de temáticas e estilos literários diversos.

Nessa perspectiva, observa-se que a literatura ficcional, pode ser considerada um dos maiores ativos do conhecimento nas bibliotecas escolares, pois

Se você quer brincar com os seus leitores, a melhor maneira não é percorrer as estantes porque seu sistema de informação está mudo. Existem alternativas. A análise de assunto na literatura infantil vai ensinar o seu sistema a ouvir e falar tão bem quanto a boneca Emília de Lobato. (MOREIRA, 2006, p.13). 


\section{Competência informacional infantil}

O ser humano, atualmente inserido no processo de globalização, em conformidade com Pinheiro e Nascimento (2001) se tornou sedento por conhecimento, pois a sociedade de informação exige de todas as pessoas uma postura pró-ativa diante do processo de geração, transferência e recepção da informação. E a criança, segundo Menezes (2009) que já foi figura secundária saiu da obscuridade e tem adquirido notadamente na contemporaneidade, cada vez mais visibilidade social.

A criança conforme Pacheco (1998) é um sujeito que procura ativamente compreender o mundo que o rodeia, e trata de resolver interrogações que este mundo provoca. É ainda um sujeito que aprende, basicamente, por suas próprias ações sobre os objetos do mundo, e que constrói suas próprias categorias de pensamento ao mesmo tempo em que organiza seu mundo.

A partir da compreensão de que crianças também possuem necessidades de informação, principalmente nos dias de hoje, em que estas já nascem em um mundo de informações imediatas, impulsionado pelo avanço das tecnologias da informação e da comunicação, que são desenvolvidas para cada vez mais em disseminar grandes quantidades de informação em espaços de tempo cada vez menores, e desta forma se deparam com uma miríade de recursos informacionais disponíveis pelo simples pressionamento de um botão, faz-se necessário analisar o comportamento informacional deste usuário.

Tal compreensão demonstra, em consonância com Campello (2006), que é possível e necessário familiarizar os alunos desde cedo com o aparato informacional do mundo letrado, desde que respeitando seu estágio de desenvolvimento, estimulando assim a competência informacional infantil.

O termo competência foi usado inicialmente de acordo com Brandão (1999) para designar um fim jurídico, no sentido de julgamento, posteriormente segundo Miranda (2004) o conceito se expandiu e passou a descrever a capacidade de alguém, a respeito de um assunto específico. Com as mudanças ocorridas no mundo do trabalho, o termo foi assimilado pela linguagem empresarial, conforme afirmam Fleury e Fleury (2001) para descrever a qualidade dos indivíduos que são capazes de realizar determinado trabalho. E em seguida, com os avanços na área de Tecnologia da informação e da Comunicação, o termo também passou a 
definir a habilidade para lidar com a informação, ou seja, competência informacional (MIRANDA, 2004, p.113).

Por outro lado, a pedagogia também iniciou uma reflexão sobre a necessidade de mudanças educacionais, pois como estava previsto na Constituição Brasileira de 1988 Capítulo III, artigos 205 a 217 - a Lei de Diretrizes e Bases da Educação Nacional (LDBEN) $\mathrm{n}^{\circ} 9.324$ de 20 de dezembro de 1996 detalha e especifica a respeito dessas necessidades de transformar os saberes em competências para adequar os aprendizes à sociedade da informação. E para o Conselho Nacional de Educação, conforme afirma ZAINKO (2002, p. 42):

[...] as competências podem ser definidas como a capacidade de mobilizar diversos recursos cognitivos para enfrentar um tipo de situação. Esses recursos cognitivos podem ser conhecimentos teóricos, um saber fazer prático, valores, julgamentos, intuições baseadas na experiência, habilidades, percepções, avaliações e estimativas. O importante é que para ser competente uma pessoa precisa integrar tudo isso e agir na situação de modo pertinente. A competência, portanto só tem sentido no contexto de uma situação.

A partir disso, diversas mudanças têm sido propostas para adequar os currículos escolares aos parâmetros exigidos pela atual sociedade. Isso pode ser comprovado pelo livro de introdução aos Parâmetros Curriculares Nacionais (PCN) que indicam que os alunos dos anos iniciais do Ensino Fundamental sejam capazes de "saber utilizar fontes de informação e recursos tecnológicos para adquirir e construir conhecimentos” (BRASIL, 1997, p.69).

Sendo assim, é possível compreender, como afirmam Fialho e Andrade (2007) que o desenvolvimento de competências informacionais é fundamental para auxiliar os aprendizes a tomar suas decisões sobre, por exemplo, em quais informações confiar, do que duvidar, o que merece atenção, o que é pertinente e o que rejeitar.

Caracterizada por uma abundância informacional nunca vista antes, essa sociedade vai exigir que os indivíduos desenvolvam habilidades específicas para lidar com a informação. E para Campello (2009), a competência informacional é exatamente o conjunto de habilidades necessárias para localizar, interpretar, analisar, sintetizar, avaliar e comunicar informação, esteja ela em fontes impressas ou eletrônicas.

Existe um modelo criado por Michael Einsenberg e Robert Berkowitz, o The Big 6, que segundo Teixeira e Lins (2010) aplica-se a estudantes que precisam ser mais eficientes em suas pesquisas, e por isso precisam adquirir, como sugerem seus criadores, seis habilidades vitais para a sobrevivência no século XXI: 
Quadro 01 - Modelo "The Big 6”

\begin{tabular}{|l|l|l|}
\hline \multicolumn{1}{|c|}{ Etapa } & \multicolumn{1}{c|}{ Ação1 } & \multicolumn{1}{c|}{ Ação 2 } \\
\hline Definição da tarefa & Definir o problema da informação & Identificar a informação necessária \\
\hline Estratégia de busca da informação & Determinar todas as possibilidades de fontes & Selecionar as melhores fontes \\
\hline Localizar e acessar & Localizar fontes (intelectualmente e fisicamente) & Encontrar informações dentro das fontes \\
\hline Uso da informação & Dedicação (isto é, ler, ouvir, ver, tocar). & Extrair a informação relevante \\
\hline Síntese & Organizar de múltiplas fontes & Atualizar a informação \\
\hline Avaliação & Julgar o resultado (efetividade) & Julgar o processo (eficiência) \\
\hline
\end{tabular}

Fonte: Eisenber; Berkowitz, 2010 apud Teixeira; Lins, 2010.

Em relação às competências informacionais de crianças e à organização da informação nas bibliotecas escolares, existe ainda um programa de aprendizagem de Kuhlthau (2006), que segundo Campello (2008, p.8), “visa desenvolver nas crianças, de forma gradual, desde o início de sua escolarização, habilidades para localizar, selecionar e interpretar informação.

Para Kuhlthau (2006) existem duas habilidades principais a serem desenvolvidas nas crianças a respeito da biblioteca escolar: de localização e de interpretação. As habilidades de localização ajudam o entendimento dos alunos sobre como os materiais são organizados, o que lhes possibilita a localização de uma informação ou um material específico e as habilidades de interpretação ajudam os alunos a entender o conteúdo e a forma de usar os materiais.

Através da execução deste programa nas bibliotecas escolares, acredita-se que as crianças poderão se preparar melhor para viver numa sociedade caracterizada por mudanças e contradições, ou seja, aprendendo a pensar de forma lógica e criativa, a solucionar problemas, a usar informações e comunicar-se efetivamente, como salienta Campelo (2008).

Assim sendo, em concordância com o pensamento de Carvalho (2008), a biblioteca escolar, deve ser pensada como um lugar de criação e compartilhamento de experiências, no qual as crianças e os jovens podem criar e não apenas consumir cultura, para então, formar um leitor crítico, que buscará vida afora a ampliação de suas experiências existenciais através da leitura. 


\section{Considerações Finais}

Como pode ser visto a organização da informação em bibliotecas escolares, pode sim fazer a diferença. Isto porque, tal arranjo favorece a recuperação da informação de forma independente, e por isso auxilia o processo de aprendizagem das crianças, de um modo geral e em particular àquelas dos anos iniciais do ensino fundamental, não só para as pesquisas escolares, mas para toda vida acadêmica.

No entanto, como foi relatado, ainda não há um consenso entre os melhores métodos e sistemas a serem utilizados neste ambiente, porém é unânime a necessidade de se preparar o espaço, o acervo e os serviços para atender as necessidades informacionais de crianças e adolescentes.

Considera-se um importante avanço a existência do vocabulário específico para obras ficcionais, assim como as demais experiências relatadas sobre a indexação de literatura infantil, visto que tais obras compõem a maior parte dos acervos das bibliotecas escolares. Estes exemplos poderão ser utilizados como modelos para outras bibliotecas escolares, e demonstra o interesse de pesquisadores pelo assunto.

Contudo, fica o desejo que a biblioteca escolar, possa cada vez mais, oferecer serviços de qualidade, por meio da cooperação entre professores e bibliotecários habilitados, da democratização do acesso ao conhecimento e da formação de leitores críticos, questionadores e conscientes de seu papel no complexo ambiente informacional da atual sociedade.

Para tanto, será indispensável enxergar a criança como construtora de cultura, capaz de criar e transformar informações e vivências, não apenas no ambiente educativo promovido pela escola, mas também fora dela. Serão necessários, portanto, estudos sobre o comportamento e necessidades informacionais do público infantil, para subsidiar a indicação de diretrizes eficazes para a organização da informação nas bibliotecas escolares. 
Referências

ANTUNES, Celso. Trabalhando habilidades: construindo ideias. São Paulo: Scipione, 2002.

BARBOSA, Sidney; MEY, Eliane Serrão Alves; SILVEIRA, Naira

Christofoletti. Vocabulário controlado para indexação de obras ficcionais. Brasília:

Briquet de Lemos, 2005.

BRANDÃO, Hugo P. Gestão baseada nas competências: um estudo sobre competências profissionais na indústria bancária. 1999. 158 f. Dissertação (Mestrado) - Universidade de Brasília, Brasília, 1999.

BRASIL. Constituição da República Federativa do Brasil de 1988. Disponível em < www.planalto.gov.br> Acesso em: 20 out. 2011.

BRASIL. Lei de Diretrizes e Bases da Educação Nacional nº 9.394, de 20 de dezembro de 1996. Disponível em <www.planalto.gov.br>. Acesso em: 20 out. 2011.

Secretaria de Educação Fundamental. Parâmetros curriculares nacionais:

introdução aos parâmetros curriculares nacionais / Brasília: MEC/SEF, 1997.126p.

Disponível em: <http://portal.mec.gov.br/seb/arquivos/pdf/livro01.pdf>. Acesso em: 04 nov. 2011.

CALDIN, Clarice Fortkamp. A função social da leitura infantil. Encontros Bibli: Revista Eletrônica de Biblioteconomia e Ciência da Informação, Florianópolis, v. 15, n. 1, set. 2003. Disponível em: <http://www.periodicos.ufsc.br/index.php/eb/article/view/1518924.2003v8n15p47/5235>. Acesso em: 10 nov. 2011.

CAMPELLO, Bernardete. A competência informacional na educação para o século XXI. In:

A biblioteca escolar: temas para uma prática pedagógica. 2.ed. Belo Horizonte: Autêntica, 2008, p.07-12.

A escolarização da competência informacional. Revista Brasileira de

Biblioteconomia e Documentação: Nova Série, São Paulo, v. 2, n. 2, p. 63-77, dez. 2006. Disponível em: <http://www.febab.org.br/rbbd/index.php/rbbd/article/view/18/6>. Acesso em: 25 out. 2011.

Letramento informacional no Brasil: práticas educativas de bibliotecários em escolas de ensino básico. 2009. 208 f. Tese (Doutorado em Ciência da Informação) Universidade Federal de Minas Gerais, Escola de Ciência da Informação, Belo Horizonte, 2009. Disponível em: <http://gebe.eci.ufmg.br/downloads/tese\%20campello\%202009.pdf>. Acesso em: 20 out. 2011.

(Coord.). Biblioteca escolar como espaço de produção do conhecimento:

parâmetros para bibliotecas escolares. Belo Horizonte: UFMG/ECI/GEBE, 2010. Disponível em:

$<$ http://gebe.eci.ufmg.br/index.php?option=com_content\&view=article\&id=13\&Itemid=11 > . Acesso em: 10 nov. 2011. 
CARVALHO, Maria da conceição. Escola, biblioteca e leitura. In: Campelo, Bernadete (Org.). A biblioteca escolar: temas para uma prática pedagógica. 2. ed. Belo Horizonte: Autêntica, 2008. p.21-24.

COSTA, Maria Leonor L. F. Pereira da. Definição de uma política de indexação numa biblioteca escolar e a recuperação da informação. 2009. 165 f. Dissertação (Mestrado em Ciências da Documentação e Informação)-Universidade de Lisboa, Faculdade de Letras, Lisboa, 2009. Disponível em: <http://repositorio.ul.pt/handle/10451/395>. Acesso em: 12 nov. 2011.

IFLA/UNESCO. Diretrizes para a biblioteca escolar. 2005. Disponível em: $<$ http://www.ifla.org/files/school-libraries-resource-centers/publications/school-libraryguidelines/school-library-guidelines-pt_br.pdf >. Acesso em: 12 nov. 2012.

FIALHO, Janaína Ferreira; ANDRADE, Maria Eugênia A. Comportamento informacional de crianças e adolescentes: uma revisão da literatura estrangeira. Ciência da Informação, Brasília, v. 36, n. 1, p. 20-34, jan./abr. 2007. Disponível em:

<http://www.scielo.br/pdf/ci/v36n1/a02v36n1.pdf>. Acesso em: 25 out. 2011.

FLEURY, A.; FLEURY, M. T. L. Estratégias empresariais e formação de competências: um quebra-cabeça caleidoscópico da indústria brasileira. 2. ed. São Paulo : Atlas, 2001.

FUJITA, Mariângela Spotti Lopes. A leitura documentária do indexador: aspectos cognitivos e lingüísticos influentes na formação do leitor profissional. Marília, 2003. $321 \mathrm{f}$. Tese (Livre-docência em Análise Documentária e Linguagens Documentárias Alfabéticas) - Faculdade de Filosofia e Ciências, Universidade Estadual Paulista Júlio de Mesquita Filho.

HAUENSTEIN, Deise Maria; SANTINI, Luciane; KUSE, Mara. Sinalização. [artigo]. 2003. Disponível em: <http://campus.fortunecity.com/mcat/102/sinaliza.htm>. Acesso em: 26 jul. 2011.

HILLESLIEINI, Araci Isaltina de Andrade; FACHIN, Gleisy Regina Bories. Biblioteca escolar: relato de experiência. Rev. ACB: Biblioteconomia em Santa Catarina, v. 5, n. 5, 2000, p.90-103. Disponível em:

<http://revista.acbsc.org.br/index.php/racb/article/download/349/413 > . Acesso em:16 nov. 2011.

HOFFMAN, Elisangela; PEREIRA, Magda Chagas. Biblioteca escolar: carências e possibilidades. EXTENSIO - Revista Eletrônica de Extensão, UFSC, n. 4, 2006.

Disponível em: <http://www.periodicos.ufsc.br/index.php/extensio/article/view/5587>. Acesso em: 22 nov. 2011.

KIESER, Herta; FACHIN, Gleisy Regina Bóries. Biblioteca escolar: espaço de interação entre bibliotecário-professor-aluno-informação-um relato. [Artigo]. 2004. Disponível em: $<$ http://ufsc.gov.br>. Acesso em: 15 mar. 2011.

KUHLTHAL, Carol. Como usar a biblioteca na escola: um programa de atividades para o ensino fundamental. 2. ed. Belo Horizonte: Autêntica, 2006. 304 p.

LEITE, Sabrina Dedé de Castro. Classificação em biblioteca infantil. 33 f. Monografia. Curso de Biblioteconomia. Brasília, 2001. 
MENEZES, K. L. M. Conversando com crianças: posicionamentos e sentidos em construção sobre família em contextos de conflito na justiça. Dissertação (Mestrado em Psicologia), Programa de Pós-Graduação em Psicologia. Universidade Federal de Pernambuco - UFPE, 2009.

MILANESI, Luiz. Ordenar para desordenar: centros de cultura e bibliotecas públicas. 2. ed. São Paulo: Brasiliense, 1989.

MIRANDA, Silvânia Vieira. Identificando competências informacionais. Ciência da Informação. Brasília, v.33, n.2, p.112-122, mai./ago.2004. Disponível em: <http://www.scielo.br/pdf/ci/v33n2/a12v33n2.pdf>. Acesso em: 25 out. 2011.

MOREIRA, Margareth Egídia. Análise de assunto da literatura ficcional infantil: categorias para ler o que você tem. 2006, 156 f. Dissertação (Mestrado em Ciência da Informação) - Universidade Federal de Minas Gerais, Escola de Ciência da Informação. 2006. Disponível em <http://www.bibliotecadigital.ufmg.br/dspace/bitstream/1843/VALA6T7RNC/1/mestrado margareth eg dia moreira parcial.pdf>. Acesso em: 12 out. 2011.

PACHECO, Elza Dias. Televisão, criança, imaginário e educação: dilemas e diálogos. Campinas: Papirus, 1998.

PIMENTEL, Graça. Biblioteca escolar. Brasília: Universidade de Brasília, 2007. Disponível em: http://portal.mec.gov.br/seb/arquivos/pdf/profunc/biblio esc.pdf. Acesso em 10 nov. 2011.

PINHEIRO, Edna Gomes; NASCIMENTO, Robéria Nádia Araújo. Informação: a força que antecipa o futuro. Informação \& Sociedade: estudos, v. 11, n. 2, 2001. Disponível em: <http://www.ies.ufpb.br/ojs2/index.php/ies/article/view/299/222>. Acesso em: 10 nov. 2011.

SILVA, Ana Cristina Oliveira e. A biblioteca escolar e o acesso ao conhecimento: classificar e indexar. 2002. Disponível em:

$<$ http://eprints.rclis.org/bitstream/10760/9106/1/A_Biblioteca_Escolar_e_o_acesso_ao_conhecimento. pdf>. Acesso em: 20 nov. 2011.

TEIXEIRA, Fábio Augusto Guimarães, LINS, Greyciane Souza Lins. Competência informacional em tempos de Web. In: ROBREDO, Jaime; BRÄSCHER, Marisa (Orgs.). Passeios pelo bosque da informação: estudos sobre a representação e organização da informação e do conhecimento. Brasília DF: IBICT, 2010. 334 p. Disponível em: <http://www.ibict.br/publicacoes/eroic.pdf>. Acesso em: 10 out. 2011.

VIANNA, Márcia Milton. A organização da coleção. In: CAMPELLO, Bernardete (Org). A biblioteca escolar: temas para uma prática pedagógica. 2. ed. Belo Horizonte: Autêntica, 2008. p.43-46.

ZAINKO, Maria Amélia Sabbag. Dos saberes às competências: construindo um novo processo de formação. Revista Diálogo Educacional, v. 3, n.5 p.29-48, jan./abr.2002. Disponível em: <http://www2.pucpr.br/reol/index.php/DIALOGO?dd1=770\&dd99=view $>$. Acesso em: 25 out. 2011. 